\title{
Exploring the link between diabetes and pancreatic cancer
}

\section{Margherita Pizzato, Federica Turati, Valentina Rosato \& Carlo La Vecchia}

To cite this article: Margherita Pizzato, Federica Turati, Valentina Rosato \& Carlo La Vecchia (2019): Exploring the link between diabetes and pancreatic cancer, Expert Review of Anticancer Therapy, DOI: $10.1080 / 14737140.2019 .1642109$

To link to this article: https://doi.org/10.1080/14737140.2019.1642109

Accepted author version posted online: 09 Jul 2019.

Submit your article to this journal $\pi$

View Crossmark data $\nearrow$ 
Publisher: Taylor \& Francis \& Informa UK Limited, trading as Taylor \& Francis Group

Journal: Expert Review of Anticancer Therapy

DOI: $10.1080 / 14737140.2019 .1642109$

\section{Special report}

Exploring the link between diabetes and pancreatic cancer

Margherita Pizzato ${ }^{1}$, Federica Turati ${ }^{1}$, Valentina Rosato ${ }^{2}$ and Carlo La Vecchia ${ }^{1} *$

${ }^{1}$ Department of Clinical Sciences and Community Health, Università degli Studi di Milano, via Vanzetti 5, 20133 Milan, Italy

${ }^{2}$ Unit of Medical Statistics and Biometry, Fondazione IRCCS Istituto Nazionale dei Tumori di Milano, Via G. Venezian 1, 20133, Milano, Italy

*Correspondence to: Carlo La Vecchia, Department of Clinical Sciences and Community Health, Università degli Studi di Milano, via Vanzetti 5, 20133 Milan, Italy, Email: carlo.lavecchia@unimi.it 


\begin{abstract}
Introduction: Epidemiological studies indicate an association between type 2 diabetes and pancreatic cancer but the complex and multidirectional relationship between them remains unclear.

Areas covered: We summarized epidemiological evidence on diabetes and pancreatic cancer exploring the time-risk relationship. We described mechanisms linking long-standing diabetes to pancreatic cancer. We discussed pancreatic cancer-associated diabetes and its implication in the early detection of pancreatic cancer.

Expert opinion: The markedly increased risk of pancreatic cancer in patients with new-onset diabetes compared with long-standing diabetes indicates a complex and bidirectional connection, with long-standing diabetes being a predisposing factor for pancreatic cancer (increasing the risk of the malignancy 1.5- to 2fold) and new-onset diabetes an early manifestation of the tumour. Identifying clinical features and biomarkers to distinguish pancreatic cancer-associated diabetes from type 2 diabetes is an important goal to improve management and survival of this cancer. Imaging (MRI) for middle age patients with new-onset diabetes may be considered.
\end{abstract}

Keywords: pancreatic cancer; review; type 2 diabetes; type $3 c$ diabetes

\title{
Article highlights
}

- Pancreatic cancer is frequently recognized at an advanced stage and has a dismal prognosis.

- Epidemiological studies indicate a complex and multidirectional relationship between type 2 diabetes and pancreatic cancer.

- The risk of pancreatic cancer is greatest early after the diagnosis of diabetes and then it decreases, while remaining elevated many years after the diagnosis.

- Time-related aspects of the association between diabetes and pancreatic cancer suggest that longstanding diabetes is a risk factor for pancreatic cancer, increasing the risk 1.5- to 2-fold, while newonset diabetes is an early manifestation of the tumour.

- Possible mechanisms for a direct link between long-standing diabetes and pancreatic cancer include resistance and compensatory hyperinsulinemia, elevated levels of circulating insulin-like growth factors, hyperglycemia and low chronic inflammation.

- The association between long-standing diabetes and pancreatic cancer may be in part due to shared risk factors between such two conditions, namely overweight/obesity, as well as to the increased medical surveillance of patients with a diagnosis of diabetes or pancreatic cancer.

- Pancreatic cancer-associated diabetes is likely a paraneoplastic effect.

- Diabetes caused by pancreatic cancer may be a clinical marker of underlying asymptomatic cancer. Identify clinical features and biomarkers to distinguish cancer-associated from type 2 diabetes may allow for earlier detection of pancreatic cancer, and hence improve management and survival. 


\section{Introduction}

Over $90 \%$ of pancreatic cancers are adenocarcinomas of the exocrine pancreas. The adenocarcinoma of the exocrine pancreas is an aggressive tumor frequently recognized at advanced stage [1]. Therapies often have an unsatisfactory impact and the 5 -year relative survival rate is $<10 \%$ ( $3 \%$ for metastatic cancer) [2]. In contrast to most other cancers, mortality due to pancreatic cancer has not declined over the most recent years [3-6].

Tobacco smoking is an established cause for pancreatic cancer [7], being responsible for $15-25 \%$ of cancers in various populations [7-10]. Other risk factors include history of (chronic) pancreatitis, obesity, diabetes and metabolic syndrome, heavy alcohol consumption and, possibly, selected aspects of diet [11-13], although the issue of diet and pancreatic cancer remains largely unclear.

The association between diabetes mellitus and pancreatic cancer has been noted since the mid' $1800 \mathrm{~s}$ [14], yet the complex and multidirectional relationship remains unclear. A higher than 2-fold increase in risk of pancreatic cancer was reported by earlier studies for diabetic patients compared to individuals without diabetes [15-18]. A real association is likely to exist [19], although this is probably more modest than previously supposed [20]. Studies assessing time-related aspects consistently indicate a negative relationship between diabetes duration and the risk of pancreatic cancer, with a peak rise in risk early after the diagnosis of diabetes that progressively decreases, while remaining elevated for many years. Such observations suggest bidirectional causality, indicating that diabetes is associated with an increased risk of pancreatic cancer and which may be the result of (subclinical) malignancy [21].

We herein summarize meta-analyses on the association between diabetes (mainly diabetes type II) and pancreatic cancer and discussed the largest original epidemiological studies that have been published over recent years, with the aim of providing a quantification of the association, and of the related time-risk relationship. We also discussed mechanisms linking long-standing diabetes to pancreatic cancer, pancreatic cancer-associated diabetes and its potential implications in the early detection of this cancer.

\section{Epidemiological studies on diabetes and pancreatic cancer}

Since the 1980s, several studies investigated the association between type 2 diabetes and the risk of pancreatic cancer. Findings of these studies have been reviewed and summarized in various reports $[11,19,20,22-29]$, including at least 5 meta-analyses [20,22-24,27] (Table 1).

A meta-analysis, published in 1995, found a doubled risk for subjects with diabetes based on 20 studies [22]. In 2005, a meta-analysis of 36 studies estimated a summary relative risk (RR) of pancreatic cancer of 1.82 (95\% confidence interval, $\mathrm{Cl}, 1.66-1.89$ ) for diabetic patients compared to non-diabetics [20]. Patients diagnosed with diabetes within 4 years prior to cancer diagnosis had a $50 \%$ greater risk of pancreatic cancer compared to patients with a longer history of the disease. The RR of patients with diabetes for 10 years or over was around 1.5. A subsequent meta-analysis of 35 cohort studies showed a summary RR for diabetes of $1.94(95 \% \mathrm{Cl}, 1.66-2.27)$ with the results being consistent after body mass index (BMI) and smoking adjustment. This meta-analysis also found an inverse relationship between the duration of diabetes and the risk of pancreatic cancer [23]. Based on 50 cohort and 39 case-control studies published up to 2013, Batabyal. et al [24] estimated a summary RR of pancreatic cancer for diabetic subjects of $1.97(95 \% \mathrm{Cl}, 1.78$ 2.18). This was similar in studies adjusting for smoking or not. As in the previous reports, the risk of pancreatic cancer was markedly increased after diabetes diagnosis; it then decreased, but remained elevated by $36 \%$ long after the diagnosis. Another meta-analysis, published in 2015 , found a $60 \%$ increased pancreatic cancer risk for duration of diabetes $\geq 2$ years versus no diabetes. For diabetes duration $\geq 10$ years, there was a $50 \%$ increase in risk [27]. Publication bias did not affect those results [23,27].

In 2015, an umbrella review on type 2 diabetes and cancer [30] reported that the association with diabetes was not convincing for pancreatic cancer, as well as for a number of other cancer types. A likely explanation was the use of very stringent criteria to define a valid and "robust" association [31]. Specifically, pancreatic cancer was not included among cancers with convincing association with diabetes mainly because the $95 \%$ prediction interval included unity [23].

Since the publication of the last meta-analysis, several epidemiological investigations have become available. Among them, a pooled analysis of 15 case-control studies (Pancreatic Cancer Case-Control Consortium, Panc4), 9 of which already considered in the previous meta-analysis by Batabyal et al [24], included about 8300 cases and almost 14,000 controls and estimated an overall odds ratio (OR) of 1.90 
(95\% Cl, 1.72-2.09) for history of diabetes 2 or more years before cancer diagnosis, after allowance for the most relevant risk factors for pancreatic cancer, including BMI, alcohol, smoking and history of pancreatitis [32]. The association between diabetes and pancreatic cancer was independent from BMI and smoking. Pancreatic cancer risk decreased as time since diagnosis of diabetes increased, with a ten-fold excess risk for new onset diabetes and a significant $30 \%$ elevated risk still evident 20 or more years after diabetes diagnosis. The ORs for diabetes duration were $10.32(95 \% \mathrm{Cl}, 7.48-14.23)$ for $<1$ year, $3.68(95 \% \mathrm{Cl}, 2.84-$ 4.77) for 1 to $<2$ years, $2.92(95 \% \mathrm{Cl}, 2.44-3.50)$ for 2 to $<5$ years, $1.84(95 \% \mathrm{Cl}, 1.54-2.20)$ for 5 to $<10$ years, $1.69(95 \% \mathrm{Cl}, 1.36-2.09)$ for 10 to $<15$ years, $1.54(95 \% \mathrm{Cl}, 1.17-2.03)$ for 15 to <20 years, and 1.30 $(95 \% \mathrm{Cl}, 95 \% \mathrm{Cl} 1.03-1.63)$ for 20 years or over.

A further pooled analysis of 19 cohorts within the Asia Cohort Consortium (including the JACC $[33,34]$ and JPHC cohorts [35], already considered in previous meta-analyses [24,27]), including data from over 770,000 participants and 2546 deaths from pancreatic cancer, found an overall hazard ratio (HR) of pancreatic cancer death of $1.53(95 \% \mathrm{Cl}, 1.32-1.77)$, after the allowance for major confounders, including $\mathrm{BMI}$ and smoking [36]. The corresponding HR after excluding the first 3 years of follow-up was 1.57 (95\% Cl, 1.341.83). Although information on the type of diabetes was not available, it is likely that type 2 diabetic patients represented the large majority of diabetics in the dataset, since type 1 diabetes accounts for less than $3 \%$ of total diabetes in Asia [37]. In that pooled-analysis, the association between diabetes and pancreatic cancer death was somewhat stronger among individuals with $B M l<22.8 \mathrm{~kg} / \mathrm{m}^{2}$. In any case, the HR for diabetes remained significantly elevated even among individuals with a higher BMI. In addition, the risk of pancreatic cancer death was (nonsignificantly) higher when duration of diabetes at baseline was $<5$ years (HRs 1.62 for $<5$ years and 1.21 for a longer duration).

The US Women's Health Initiative (WHI) observational study [38], based on over 156,000 postmenopausal women and 1000 pancreatic cancer cases, estimated a moderate increased HR for diabetes after the allowance for waist circumference (HR: 1.30, 95\% Cl, 1.01-1.66).

In addition, several cohorts based on administrative datasets or cancer/diabetes registries have been recently published [39-49]. While offering important advantages in terms of sample size and representativeness of the populations, such studies were shadowed by the limited availability of information on confounding factors, specifically tobacco smoking and BMI. Those studies generally confirmed the direct association between diabetes and pancreatic cancer, with RR estimates for any duration of diabetes of the order of 2.0-3.0. Some of them also supported the inverse association with time since diabetes diagnosis $[40,41,43,47,49]$. In particular, in a cohort of 2.3 million adults from a health maintenance organization in Israel, with almost 2000 incident cases of pancreatic cancer, the HR of pancreatic cancer was over 15 in the first year following diabetes diagnosis, over 5 in years $1-<2$ and around 3 (still significant) in years 2-11 following diabetes diagnosis [41]. In addition, an updated of a nationwide Swedish cohort based on over 380,000 individuals with a diagnosis of type 2 diabetes in the period 19642010 and 2027 incident pancreatic cancers found standardized incidence ratios (SIR) decreasing as followup increased, ranging from 8.8 for $<1$ year to 1.47 (still significant) for 10 years and over [47].

Two recent meta-analyses addressed possible sex differences in the association between diabetes and pancreatic cancer [25,50]. Based respectively on 24 [25] and 31 cohorts [50], they found similar RRs of pancreatic cancer in diabetic men and women. 


\section{Expert opinion}

Epidemiological evidence indicates a direct association between type 2 diabetes and pancreatic cancer and supports an inverse relation with diabetes duration. In particular, the observed risk of pancreatic cancer is greatest early after the diagnosis of diabetes and it progressively decreases, while remaining elevated many years after diabetes detection. The markedly higher risk of pancreatic cancer in patients with new-onset diabetes compared with long-standing diabetes suggests a complex and bidirectional connection: on one side, long-standing diabetes is a predisposing factor for pancreatic cancer development, increasing the risk of the malignancy around 1.5- to 2-fold; on the other side, new-onset diabetes may be a consequence or an early manifestation of pancreatic cancer [51]. In the latter context, diabetes secondary to pancreatic cancer usually develops within 24-36 months prior to the diagnosis of the cancer [52].

\subsection{Long-standing diabetes}

Several mechanisms have been suggested to clarify the association between long-standing diabetes and pancreatic cancer.

A hypothesis includes insulin resistance and compensatory high levels of insulin secretion (overproduced in type 2 diabetes mellitus until $\beta$-cell failure) [51,53]. In a pooled-analysis of 5 US prospective cohorts, the RRs for the upper versus lower quintile were $1.57(95 \% \mathrm{Cl}, 1.08-2.30)$ for prediagnostic serum insulin and $2.22(95 \% \mathrm{Cl}, 1.50-3.29)$ for prediagnostic proinsulin. Such associations became progressively stronger considering only cases developed after 5 or 10 years of follow-up, indicating that elevated biomarkers were not likely due to preclinical cancer [54]. Similarly, a prospective study estimated a two-fold pancreatic cancer risk (95\% Cl, 1.0-3.9) among individuals in the upper versus the lower quartile of insulin level, after excluding patients diagnosed within the first 5 years of follow-up, and also reported direct associations with baseline insulin resistance and higher glucose concentration [55]. Again, the associations were stronger after a longer time of follow-up. A role of hyperinsulinemia in the risk of pancreatic cancer is also supported by the observation that obese patients undergoing bariatric surgery (who typically show hyperinsulinemia) had a $50 \%$ reduction in the risk of pancreatic cancer compared to obese nonsurgical patients [56]. Both a direct effect of insulin and an indirect action involving growth hormone (GH)/insulin-like growth factor (IGF) axis could explain the increase in risk of hyperinsulinemic patients. Pancreatic $\beta$-cells release insulin in the intrapancreatic portal vessels [51] that lap acinar and ductal cells [57]. Thus, insulin exerts a proxicrine effect on receptors of exocrine pancreatic cells that, once activated, convey survival and proliferation signals [19] involved in carcinogenesis [58]. Insulin may also indirectly promote cancerogenesis acting on GH/IGF axis [19]. IGF receptors, expressed in pancreatic cancer cells, codify antiapoptotic and angiogenic signals which promote tumor development. Insulin increases levels of free and bioactive IGF-1, reducing hepatic production of IGF binding protein (IGFBP). Further, IGF-1 and insulin receptors are structurally similar, thus insulin and IGF-1 could activate both receptors. High IGF1 and hyperinsulinemia, that occurs in insulin resistant individuals, act synergically in promoting cancerogenesis [28]. In line with the hyperinsulinemic hypothesis [53], treatments improving insulin resistance, namely metformin, might reduce pancreatic cancer risk, whereas therapies that stimulate endogenous release of insulin, such as sulfunylureas, may increase the risk [59], although evidence is unclear [60]. In addition, a possible role of hyperglycemia in the diabetes-pancreatic cancer association has been suggested [28,53]. Hyperglycemia can attenuate antioxidant enzyme activity and enhance free radical formation, leading to a state of oxidative stress. Hyperglycemia is associated with increased levels of advanced glycation end products (AGE), whose receptor binds several ligands implicated in inflammation and cancer process [51]. Moreover, hyperglycaemic conditions may facilitate neoplastic proliferation [61]. Nonetheless, glucose uptake mechanisms may not add a further growth advantage [19].

Overweight, that frequently characterized type 2 diabetes, could play a crucial role in carcinogenesis $[62,63]$. Adipose tissue is a complex endocrine organ able to secrete a variety of bioactive molecules (cytokines, free fatty acids, TNFalfa, plasminogen activator inhibitor-1 (PAI-1) and adiponectin) which may lead malignant transformation and progression [64]. Further, adipose tissue microenvironment promotes concomitant systemic endocrine alterations (obesity-related insulin resistance, hyperinsulinemia, sustained hyperglycemia) which, in turn, are involved in cancer development [65]. However, an increased risk of pancreatic cancer among diabetic subjects was evident also after adjusting for anthropometric factors (mainly BMI) $[7,23,36,38]$ and in subgroup defined by BMI $[7,36]$, thus indicating that obesity is unlikely to 
explain the observed association, although some degree of under-adjustment is possible. Further, RRs for the diabetes-pancreatic cancer association are similar in studies adjusting and not adjusting for smoking $[23,24]$. In addition, the direct association between prediabetes and pancreatic cancer risk [66] supports the relationship between diabetes and pancreatic cancer.

Diagnostic bias may contribute in part to the observed increased risk. Indeed, an increased medical surveillance has been documented for patients with type 2 diabetes [67].

The risk of the malignancy declines with the increasing duration of diabetes. Such downward trend in risk might be explained through a decreased role of diagnostic bias, besides a possible additional role of a decreased secretion of endogenous insulin, lifestyle changes after diabetes diagnosis and the use of metformin and selected glucose-lowering medications.

\subsection{New onset diabetes}

The risk of pancreatic cancer is highly increased until a couple of years from diabetes diagnosis, suggesting that the cancer itself lead to the onset of diabetes.

Pancreatic cancer-induced diabetes has been classified as pancreatogenic type $3 c$ diabetes mellitus [68]. However, only a small proportion ( $<10 \%$ ) of type $3 c$ diabetes (which accounts for $<10 \%$ of total diabetes) is attributed to pancreatic neoplasia, while the majority $(75-80 \%)$ is associated to chronic pancreatitis [51]. Concurrent diabetes and chronic pancreatitis increased the risk of pancreatic cancer by 5 - to over 30 -fold [69-71].

The hypothesis that pancreatic cancer induces diabetes is supported by the observations that roughly half of the newly diagnosed pancreatic cancer patients have diabetes at the time of diagnosis, which is frequently $(>50 \%)$ new-onset having developed over the 2-3 years preceding the diagnosis of pancreatic cancer $[52,72]$. Not all new onset diabetes is type $3 c$ diabetes mellitus (assuming that type $3 c$ diabetes mellitus is a well-defined, independent syndrome), but, in a proportion of patients with new-onset diabetes, resection of the tumor is followed by diabetes resolution [72]. In an Italian multicentric casecontrol study, diabetes was diagnosed concomitantly with pancreatic cancer in $40 \%$ of patients and within 2 years before the diagnosis of cancer in 16\% [73].

The physiopathology linking type $3 c$ diabetes mellitus to pancreatic cancer is still poorly understood. Diabetes secondary to pancreatic cancer may be the result of a glandular destruction due to tumour infiltration and ductal obstruction. However, diabetes in pancreatic cancer patients is mainly characterized by hyperinsulinemia secondary to insulin resistance. Therefore, diabetes secondary to pancreatic cancer is likely a paraneoplastic effect: mediators released by the cancer interfere with insulin secretion or insulin action [74]. This is supported by the evidence that treatments (resection or chemotherapy) of pancreatic cancer often lead to improvement in hyperglycemia [72]. In addition, a direct role of pancreatic cancer in new onset diabetes is supported by the finding that glucose tolerance improves after tumour treatment in patients with new-onset diabetes secondary to pancreatic cancer, whilst it does not improve in longstanding diabetes [75].

In any case, the peak of pancreatic cancer risk within the first years since diabetes detection may be inflated by the heightened surveillance following diabetes diagnosis.

\subsection{New onset diabetes for the early detection of pancreatic cancer}

The 5 -year relative survival rate of pancreatic cancer is around $5 \%$, and ranges between around $35 \%$ for localized cancers (which represent a small fraction of cancers) and 3\% for metastatic ones [2]. The detection of pancreatic cancer is often delayed because symptoms are often aspecific (e.g., weight loss, jaundice, nausea) and occur in an advanced stage. Thus, early detection of pancreatic cancer when it is still asymptomatic, and therapeutic options are available, is an important goal for improving pancreatic cancer management and survival.

New-onset diabetes caused by the cancer is a possible clinical marker of underlying asymptomatic pancreatic cancer. Therefore, the identification of patients with cancer-associated diabetes could offer the opportunity for the early detection of the malignancy [68]. According to a population-based cohort study, the 3-year cumulative incidence of pancreatic cancer among newly diagnosed diabetic patients aged $\geq 50$ years was $0.85 \%$, over 6 -fold higher than the general population [76]. Although mass screening for 
pancreatic cancer in all patients with new-onset diabetes is still open to discussion [77], imaging (MRI) of the pancreas may be considered for middle age and elderly subjects ( $\geq 50$ years) developing diabetes. Some further indications to distinguish pancreatic cancer-associated diabetes from other types of diabetes may derive from clinical features atypical for type 2 diabetes, such as rapidly altered glycemic indices, weight loss in the preceding months prior to diabetes onset, absence of typical characteristics of the metabolic syndrome, and family history [74]. Notably, a case-control study indicated that elevated glucose levels precede the diagnosis of pancreatic cancer by 30-36 months [78].

Two studies developed and validated clinical prediction models to identify high-risk individuals among those with newly diagnosed diabetes who might benefit from pancreatic cancer screening. One clinical model included age at diabetes diagnosis and change in weight and in blood glucose and stratified patients in 3 risk groups. The cut-off for the very high-risk group had sensitivity and specificity of $80 \%$ [79]. A further model was based on age, BMI, change in BMI, smoking, use of antidiabetic medications, serum levels of $\mathrm{HbA} 1 \mathrm{C}$, and other selected markers, and had $45 \%$ sensitivity and $94 \%$ specificity, and a positive predictive value of $2.6 \%$ [80]. However further validation is need.

It is likely that a combination of biomarkers and clinicopathologic characteristics of diabetic patients is useful in early cancer detection. Although no biomarker is currently validated to differentiate between type 2 diabetes and cancer-associated diabetes, evidence shows the potential relevance of some molecules [81]. In particular, the most convincing ones include Vanin-1 (VNN1) [82], Adrenomedullin [83], CA19-9 and CEA [84], glucagon/insulin ratio [85] and a deficient pancreatic polypeptide (PP) response to nutrient ingestion [86].

Future research may identify predictive models and/or sensitive and specific biomarkers for the identification of occult pancreatic cancer in patients with new-onset diabetes, and develop an efficient and cost-effective interventional screening protocol for newly diagnosed diabetic patients that includes imaging and/or clinical algorithms. In this context, valuable data may be generated in the next years by the Consortium for the Study of Chronic Pancreatitis, Diabetes, and Pancreatic Cancer (CPDPC). Initiated in 2015 , the CPDPC aims to assemble a cohort of 10,000 subjects $\geq 50$ years with new onset diabetes to address to the challenges posed by early detection of pancreatic cancer [87].

\section{Funding}

This work was partly supported by Department Funding and the Italian League against cancer.

\section{Declaration of interest}

The authors have no relevant affiliations or financial involvement with any organization or entity with a financial interest in or financial conflict with the subject matter or materials discussed in the manuscript. This includes employment, consultancies, honoraria, stock ownership or options, expert testimony, grants or patents received or pending, or royalties

\section{Reviewer disclosures}

Peer reviewers on this manuscript have no relevant financial or other relationships to disclose.

\section{Acknowledgments}

The authors thank their colleague Linia Patel for English revision of the manuscript. 


\section{References}

1. Garrido-Laguna I, Hidalgo M. Pancreatic cancer: from state-of-the-art treatments to promising novel therapies. Nat Rev Clin Oncol 2015;12:319-34

2. Siegel RL, Miller KD, Jemal A. Cancer statistics, 2019. CA Cancer J Clin 2019;69:7-34

3. Lucas AL, Malvezzi M, Carioli G, et al. Global Trends in Pancreatic Cancer Mortality From 1980 Through 2013 and Predictions for 2017. Clin Gastroenterol Hepatol 2016;14:1452-62.e4

4. Ma J, Siegel R, Jemal A. Pancreatic cancer death rates by race among US men and women, 1970-2009. J Natl Cancer Inst 2013;105:1694-700

5. Malvezzi M, Carioli G, Bertuccio P, et al. European cancer mortality predictions for the year 2019 with focus on breast cancer. Ann Oncol 2019;30:781-7

6. Hashim D, Boffetta P, La Vecchia C, et al. The global decrease in cancer mortality: trends and disparities. Ann Oncol 2016;27:926-33

7. Bosetti C, Lucenteforte E, Silverman DT, et al. Cigarette smoking and pancreatic cancer: an analysis from the International Pancreatic Cancer Case-Control Consortium (Panc4). Ann Oncol 2012;23:1880-8

8. Rosato V, Polesel J, Bosetti C, Serraino D, Negri E, La Vecchia C. Population attributable risk for pancreatic cancer in Northern Italy. Pancreas 2015;44:216-20

9. Parkin DM. 2. Tobacco-attributable cancer burden in the UK in 2010. Br J Cancer 2011;105 Suppl 2:S6-S13

10. Jiao L, Mitrou PN, Reedy J, et al. A combined healthy lifestyle score and risk of pancreatic cancer in a large cohort study. Arch Intern Med 2009;169:764-70

11. Maisonneuve P, Lowenfels AB. Risk factors for pancreatic cancer: a summary review of meta-analytical studies. Int J Epidemiol 2015;44:186-98

12. Hidalgo M. Pancreatic cancer. N Engl J Med 2010;362:1605-17

13. Kleeff J, Korc M, Apte M, et al. Pancreatic cancer. Nat Rev Dis Primers 2016;2:16022

14. Bright R. Cases and Observations connected with Disease of the Pancreas and Duodenum. Med Chir Trans 1833;18:1-56

15. Wynder EL, Mabuchi K, Maruchi N, Fortner JG. Epidemiology of cancer of the pancreas. J Natl Cancer Inst 1973;50:645-67

16. Whittemore AS, Paffenbarger RS, Jr., Anderson K, Halpern J. Early precursors of pancreatic cancer in college men. JChronic Dis 1983;36:251-6

17. Hiatt RA, Klatsky AL, Armstrong MA. Pancreatic cancer, blood glucose and beverage consumption. Int J Cancer 1988;41:794-7

18. Cuzick J, Babiker AG. Pancreatic cancer, alcohol, diabetes mellitus and gall-bladder disease. Int J Cancer 1989;43:415-21

19. Giovannucci E, Harlan DM, Archer MC, et al. Diabetes and cancer: a consensus report. Diabetes Care 2010;33:1674-85

20. Huxley R, Ansary-Moghaddam A, Berrington de Gonzalez A, Barzi F, Woodward M. Type-II diabetes and pancreatic cancer: a meta-analysis of 36 studies. Br J Cancer 2005;92:2076-83

21. Pannala R, Basu A, Petersen GM, Chari ST. New-onset diabetes: a potential clue to the early diagnosis of pancreatic cancer. Lancet Oncol 2009;10:88-95 
22. Everhart J, Wright D. Diabetes mellitus as a risk factor for pancreatic cancer. A meta-analysis. JAMA 1995;273:1605-9

23. Ben $Q$, Xu M, Ning X, et al. Diabetes mellitus and risk of pancreatic cancer: A meta-analysis of cohort studies. Eur J Cancer 2011;47:1928-37

24. Batabyal P, Vander Hoorn S, Christophi C, Nikfarjam M. Association of diabetes mellitus and pancreatic adenocarcinoma: a meta-analysis of 88 studies. Ann Surg Oncol 2014;21:2453-62

- A meta-analysis of 88 observational studies published up to 2013 investigating theassociation between diabetes, diabetes duration and pancreatic cancer

25. Fang HJ, Shan SB, Zhou YH, Zhong LY. Diabetes mellitus and the risk of gastrointestinal cancer in women compared with men: a meta-analysis of cohort studies. BMC Cancer 2018;18:422

26. Starup-Linde J, Karlstad O, Eriksen SA, et al. CARING (CAncer Risk and INsulin analoGues): the association of diabetes mellitus and cancer risk with focus on possible determinants - a systematic review and a meta-analysis. Curr Drug Saf 2013;8:296-332

27. Song S, Wang B, Zhang X, et al. Long-Term Diabetes Mellitus Is Associated with an Increased Risk of Pancreatic Cancer: A Meta-Analysis. PLoS One 2015;10:e0134321

28. Li D. Diabetes and pancreatic cancer. Mol Carcinog 2012;51:64-74

29. Sacerdote C, Ricceri F. Epidemiological dimensions of the association between type 2 diabetes and cancer: A review of observational studies. Diabetes Res Clin Pract 2018;143:369-77

30. Tsilidis KK, Kasimis JC, Lopez DS, Ntzani EE, loannidis JP. Type 2 diabetes and cancer: umbrella review of meta-analyses of observational studies. BMJ 2015;350:g7607

31. Satija A, Spiegelman D, Giovannucci E, Hu FB. Type 2 diabetes and risk of cancer. BMJ 2015;350:g7707

32. Bosetti C, Rosato V, Li D, et al. Diabetes, antidiabetic medications, and pancreatic cancer risk: an analysis from the International Pancreatic Cancer Case-Control Consortium. Ann Oncol 2014;25:2065-72

- A pooled-analysis of $\mathbf{1 5}$ case-control studies within the Pancreatic Cancer Case-Control Consortium (Panc4) which focused on the temporal relationship between diagnosis of diabetes and onset of pancreatic cancer

33. Khan M, Mori M, Fujino $Y$, et al, Site-specific cancer risk due to diabetes mellitus history: evidence from the Japan Collaborative Cohort (JACC) Study. Asian Pac J Cancer Prev 2006;7:253-9

34. Lin Y, Tamakoshi A, Kawamura T, et al. Risk of pancreatic cancer in relation to alcohol drinking, coffee consumption and medical history: findings from the Japan collaborative cohort study for evaluation of cancer risk. Int J Cancer 2002;99:742-6

35. Luo J, Iwasaki M, Inoue M, et al. Body mass index, physical activity and the risk of pancreatic cancer in relation to smoking status and history of diabetes: a large-scale population-based cohort study in Japan-the JPHC study. Cancer Causes Control 2007;18:603-12

36. Chen Y, Wu F, Saito E, et al. Association between type 2 diabetes and risk of cancer mortality: a pooled analysis of over 771,000 individuals in the Asia Cohort Consortium. Diabetologia 2017;60:1022-32

37. Cockram CS. The epidemiology of diabetes mellitus in the Asia-Pacific region. Hong Kong Med J 2000;6:43-52

38. Arthur R, Kabat GC, Kim MY, et al. Adiposity, history of diabetes, and risk of pancreatic cancer in postmenopausal women. Ann Epidemiol 2019;29:23-9 e1 
39. Ballotari P, Vicentini M, Manicardi V, et al. Diabetes and risk of cancer incidence: results from a population-based cohort study in northern Italy. BMC Cancer 2017;17:703

40. Berger SM, Gislason G, Moore LL, et al. Associations between metabolic disorders and risk of cancer in Danish men and women--a nationwide cohort study. BMC Cancer 2016;16:133

41. Dankner R, Boffetta P, Balicer RD, et al. Time-Dependent Risk of Cancer After a Diabetes Diagnosis in a Cohort of 2.3 Million Adults. Am J Epidemiol 2016;183:1098-106

42. Fedeli U, Zoppini G, Gennaro N, Saugo M. Diabetes and cancer mortality: a multifaceted association. Diabetes Res Clin Pract 2014;106:e86-9

43. Gini A, Bidoli E, Zanier L, et al. Cancer among patients with type 2 diabetes mellitus: A population-based cohort study in northeastern Italy. Cancer Epidemiol 2016;41:80-7

44. Harding JL, Shaw JE, Peeters A, Cartensen B, Magliano DJ. Cancer risk among people with type 1 and type 2 diabetes: disentangling true associations, detection bias, and reverse causation. Diabetes Care 2015;38:264-70

45. Kang YM, Kim YJ, Park JY, Lee WJ, Jung CH. Mortality and causes of death in a national sample of type 2 diabetic patients in Korea from 2002 to 2013. Cardiovasc Diabetol 2016;15:131

46. Lin CC, Chiang JH, Li Cl, et al. Cancer risks among patients with type 2 diabetes: a 10-year follow-up study of a nationwide population-based cohort in Taiwan. BMC Cancer 2014;14:381

47. Liu X, Hemminki K, Forsti A, Sundquist K, Sundquist J, Ji J. Cancer risk in patients with type 2 diabetes mellitus and their relatives. Int J Cancer 2015;137:903-10

48. Romon I, Rey G, Mandereau-Bruno L, et al. The excess mortality related to cardiovascular diseases and cancer among adults pharmacologically treated for diabetes--the 2001-2006 ENTRED cohort. Diabet Med 2014;31:946-53

49. Wang $\mathrm{M}, \mathrm{Hu} \mathrm{RY}, \mathrm{Wu} \mathrm{HB}$, et al. Cancer risk among patients with type 2 diabetes mellitus: a populationbased prospective study in China. Sci Rep 2015;5:11503

50. Ohkuma T, Peters SAE, Woodward M. Sex differences in the association between diabetes and cancer: a systematic review and meta-analysis of 121 cohorts including 20 million individuals and one million events. Diabetologia 2018;61:2140-54

51. Andersen DK, Korc M, Petersen GM, et al. Diabetes, Pancreatogenic Diabetes, and Pancreatic Cancer. Diabetes 2017;66:1103-10

- A review describing the current understanding of the interrelationships between diabetes, diabetes management, and pancreatic cancer, and areas where additional research is needed 52. Chari ST, Leibson CL, Rabe KG, et al. Pancreatic cancer-associated diabetes mellitus: prevalence and temporal association with diagnosis of cancer. Gastroenterology 2008;134:95-101

53. Johnson JA, Carstensen B, Witte D, et al. Diabetes and cancer (1): evaluating the temporal relationship between type 2 diabetes and cancer incidence. Diabetologia 2012;55:1607-18

- A review addressing methodological aspects underpinning the interpretations of links between diabetes and cancer incidence

54. Wolpin BM, Bao Y, Qian ZR, et al. Hyperglycemia, insulin resistance, impaired pancreatic beta-cell function, and risk of pancreatic cancer. J Natl Cancer Inst 2013;105:1027-35

55. Stolzenberg-Solomon RZ, Graubard BI, Chari S, et al. Insulin, glucose, insulin resistance, and pancreatic cancer in male smokers. JAMA 2005;294:2872-8 
56. Schauer DP, Feigelson HS, Koebnick C, et al. Bariatric Surgery and the Risk of Cancer in a Large Multisite Cohort. Ann Surg 2019;269:95-101

57. Ding XZ, Fehsenfeld DM, Murphy LO, Permert J, Adrian TE. Physiological concentrations of insulin augment pancreatic cancer cell proliferation and glucose utilization by activating MAP kinase, $\mathrm{PI} 3$ kinase and enhancing GLUT-1 expression. Pancreas 2000;21:310-20

58. Pollak M. Insulin and insulin-like growth factor signalling in neoplasia. Nat Rev Cancer 2008;8:915-28

59. Currie CJ, Poole CD, Gale EA. The influence of glucose-lowering therapies on cancer risk in type 2 diabetes. Diabetologia 2009;52:1766-77

60. Soranna D, Scotti L, Zambon A, et al. Cancer risk associated with use of metformin and sulfonylurea in type 2 diabetes: a meta-analysis. Oncologist 2012;17:813-22

61. Vander Heiden MG, Cantley LC, Thompson CB. Understanding the Warburg effect: the metabolic requirements of cell proliferation. Science 2009;324:1029-33

62. Chatterjee S, Khunti K, Davies MJ. Type 2 diabetes. Lancet 2017;389:2239-51

63. Kyrgiou M, Kalliala I, Markozannes G, et al. Adiposity and cancer at major anatomical sites: umbrella review of the literature. BMJ 2017;356:j477

64. Pothuraju R, Rachagani S, Junker WM, et al. Pancreatic cancer associated with obesity and diabetes: an alternative approach for its targeting. J Exp Clin Cancer Res 2018;37:319

65. Park J, Morley TS, Kim M, Clegg DJ, Scherer PE. Obesity and cancer--mechanisms underlying tumour progression and recurrence. Nat Rev Endocrinol 2014;10:455-65

66. Huang Y, Cai X, Qiu M, et al. Prediabetes and the risk of cancer: a meta-analysis. Diabetologia 2014;57:2261-9

67. De Bruijn KM, Ruiter R, de Keyser CE, Hofman A, Stricker BH, van Eijck CH. Detection bias may be the main cause of increased cancer incidence among diabetics: results from the Rotterdam Study. Eur J Cancer 2014;50:2449-55

68. Hart PA, Bellin MD, Andersen DK, et al. Type $3 c$ (pancreatogenic) diabetes mellitus secondary to chronic pancreatitis and pancreatic cancer. Lancet Gastroenterol Hepatol 2016;1:226-37

- A review on the epidemiology, pathogenesis, and clinical relevance of type $3 c$ diabetes secondary to chronic pancreatitis and pancreatic ductal adenocarcinoma

69. Liao KF, Lai SW, Li Cl, Chen WC. Diabetes mellitus correlates with increased risk of pancreatic cancer: a population-based cohort study in Taiwan. J Gastroenterol Hepatol 2012;27:709-13

70. Munigala S, Singh A, Gelrud A, Agarwal B. Predictors for Pancreatic Cancer Diagnosis Following NewOnset Diabetes Mellitus. Clin Transl Gastroenterol 2015;6:e118

71. Brodovicz KG, Kou TD, Alexander CM, et al. Impact of diabetes duration and chronic pancreatitis on the association between type 2 diabetes and pancreatic cancer risk. Diabetes Obes Metab 2012;14:1123-8

72. Pannala R, Leirness JB, Bamlet WR, Basu A, Petersen GM, Chari ST. Prevalence and clinical profile of pancreatic cancer-associated diabetes mellitus. Gastroenterology 2008;134:981-7

73. Gullo L, Pezzilli R, Morselli-Labate AM, Italian Pancreatic Cancer Study G. Diabetes and the risk of pancreatic cancer. N Engl J Med 1994;331:81-4

74. Sah RP, Nagpal SJ, Mukhopadhyay D, Chari ST. New insights into pancreatic cancer-induced paraneoplastic diabetes. Nat Rev Gastroenterol Hepatol 2013;10:423-33 
75. Permert J, Ihse I, Jorfeldt L, von Schenck H, Arnquist HJ, Larsson J. Improved glucose metabolism after subtotal pancreatectomy for pancreatic cancer. Br J Surg 1993;80:1047-50

76. Chari ST, Leibson CL, Rabe KG, Ransom J, de Andrade M, Petersen GM. Probability of pancreatic cancer following diabetes: a population-based study. Gastroenterology 2005;129:504-11

- A population-based cohort study estimating a $0.85 \%$ 3-year cumulative incidence of pancreatic cancer among new-onset diabetic patients aged $\geq 50$ years

77. Singhi AD, Koay EJ, Chari ST, Maitra A. Early Detection of Pancreatic Cancer: Opportunities and Challenges. Gastroenterology 2019;156:2024-40

- A review exploring the opportunities and challenges for the early detection of pancreatic cancer, with a focus on elderly patients with new-onset diabetes.

78. Sharma A, Smyrk TC, Levy MJ, Topazian MA, Chari ST. Fasting Blood Glucose Levels Provide Estimate of Duration and Progression of Pancreatic Cancer Before Diagnosis. Gastroenterology 2018;155:490-500 e2

79. Sharma A, Kandlakunta H, Nagpal SJS, et al. Model to Determine Risk of Pancreatic Cancer in Patients With New-Onset Diabetes. Gastroenterology 2018;155:730-9 e3

80. Boursi B, Finkelman B, Giantonio BJ, et al. A Clinical Prediction Model to Assess Risk for Pancreatic Cancer Among Patients With New-Onset Diabetes. Gastroenterology 2017;152:840-50 e3

81. Zhang Z, Qin W, Sun Y. Contribution of biomarkers for pancreatic cancer-associated new-onset diabetes to pancreatic cancer screening. Pathol Res Pract 2018;214:1923-8

82. Kang M, Qin W, Buya M, et al. VNN1, a potential biomarker for pancreatic cancer-associated new-onset diabetes, aggravates paraneoplastic islet dysfunction by increasing oxidative stress. Cancer Lett 2016;373:241-50

83. Aggarwal G, Ramachandran V, Javeed N, et al. Adrenomedullin is up-regulated in patients with pancreatic cancer and causes insulin resistance in beta cells and mice. Gastroenterology 2012;143:1510-7 e1

84. Guo Q, Kang M, Zhang B, Chen Y, Dong X, Wu Y. Elevated levels of CA 19-9 and CEA in pancreatic cancer-associated diabetes. J Cancer Res Clin Oncol 2010;136:1627-31

85. Kolb A, Rieder S, Born D, et al. Glucagon/insulin ratio as a potential biomarker for pancreatic cancer in patients with new-onset diabetes mellitus. Cancer Biol Ther 2009;8:1527-33

86. Hart PA, Baichoo E, Bi Y, Hinton A, Kudva YC, Chari ST. Pancreatic polypeptide response to a mixed meal is blunted in pancreatic head cancer associated with diabetes mellitus. Pancreatology 2015;15:162-6

87. Maitra A, Sharma A, Brand RE, et al. A Prospective Study to Establish a New-Onset Diabetes Cohort: From the Consortium for the Study of Chronic Pancreatitis, Diabetes, and Pancreatic Cancer. Pancreas 2018;47:1244-8 
Table 1. Summary of major meta-analyses examining the association between diabetes mellitus and pancreatic cancer.

\begin{tabular}{|c|c|c|c|c|}
\hline Reference & N. of included studies & Summary RR (95\% Cl) for diabetes & Heterogeneity $\left(p ; I^{2}\right)$ & $\begin{array}{l}\text { Summary RR }(95 \% \mathrm{Cl}) \text { for time since } \\
\text { diabetes (years) }\end{array}$ \\
\hline Song et al, 2015 [27] & $\begin{array}{l}26 \text { cohort }^{\S} \\
18 \text { case-control }^{-}\end{array}$ & $\begin{array}{l}\geq 2 \text { years since diabetes: } \\
\text { overall: } 1.64(1.52-1.78) \\
\text { cohort: } 1.56(1.42-1.71) \\
\text { nested: } 1.88(1.53-2.30) \\
\text { case-control: } 1.75(1.44-2.12)\end{array}$ & $\begin{array}{l}\text { overall: } p<0.001 ; 52.1 \% \\
\text { cohort: } p=0.001 ; 54.6 \% \\
\text { nested: } p=0.679 ; 0 \% \\
\text { case-control: } p=0.004 ; 52.9\end{array}$ & $\begin{array}{l}\geq 5 \text { (26 studies): } 1.58 \text { (1.41-1.75) } \\
\geq 10 \text { (14 studies): } 1.50 \text { (1.28-1.75) }\end{array}$ \\
\hline Batabyal et al, 2014 [24] & $\begin{array}{l}50 \text { cohort }^{\S} \\
39 \text { case-control }^{8}\end{array}$ & $\begin{array}{l}\text { overall: } 1.97 \text { (1.78-2.18) } \\
\text { cohort: } 1.88 \text { (1.71-2.07) } \\
\text { case-control: } 2.08 \text { (1.87-2.32) }\end{array}$ & $\begin{array}{l}\text { overall: NA } \\
\text { cohort: }<0.001 ; 91 \% \text {; } \\
\text { case-control: }<0.001 ; 65 \%\end{array}$ & $\begin{array}{l}<1 \text { (3 studies): } 6.69 \text { (3.80- 11.78) } \\
\text { 1-4 (21 studies) : } 1.86(1.56-2.21) \\
\text { 5-9 (23 studies): } 1.72(1.47-2.00) \\
\geq 10 \text { (28 studies): } 1.36 \text { (1.19-1.55) }\end{array}$ \\
\hline Ben et al, 2011 [23] & 35 cohort $^{\S}$ & cohort: 1.94 (1.66-2.27) & $<0.001 ; 93.6 \%$ & $\begin{array}{l}<1 \text { (3 studies): } 5.38 \text { (3.49-8.30) } \\
\text { 1-4 ( } 5 \text { studies): } 1.95 \text { (1.65-2.31) } \\
\text { 5-9 (4 studies): } 1.49 \text { (1.05-2.12) } \\
\geq 10 \text { (4 studies): } 1.47 \text { (0.94-2.31) } \\
\\
>1 \text { (14 studies): } 1.96 \text { (1.60-2.40) } \\
>5 \text { (11 studies): } 1.83 \text { (1.38-2.43) }\end{array}$ \\
\hline Huxley et al, 2005 [20] & $\begin{array}{l}19 \text { cohort }^{\S} \\
17 \text { case-control }^{\text {case }}\end{array}$ & $\begin{array}{l}\text { overall: } 1.82(1.66-1.89) \\
\text { cohort: } 1.73(1.59-1.88) \\
\text { case-control: } 1.94(1.53-2.46)\end{array}$ & $\begin{array}{l}\text { overall: } N A \\
\text { cohort: } p=0.05 \\
\text { case-control: } p=0.002\end{array}$ & $\begin{array}{l}<4 \text { (9 studies): } 2.05 \text { (1.87-2.25) } \\
\text { 5-9 (9 studies): } 1.54(1.31-1.81) \\
\geq 10 \text { (7 studies): } 1.51 \text { (1.16-1.96) }\end{array}$ \\
\hline $\begin{array}{l}\text { Everhart \& Wright, } 1995 \\
\text { [22] }\end{array}$ & $\begin{array}{l}9 \text { cohort }^{\S} \\
11 \text { case-control }^{-}\end{array}$ & $\begin{array}{l}\text { >1 year since diabetes: } \\
\text { overall: } 2.1(1.6-2.8) \\
\text { cohort: } 2.6(1.6-4.1) \\
\text { case-control: } 1.8(1.1-2.7)\end{array}$ & $\begin{array}{l}\text { overall: } p=0.003 \\
\text { cohort: NA } \\
\text { case-control: NA }\end{array}$ & $\geq 5$ (11 studies): 2.0 (1.2-3.2) \\
\hline
\end{tabular}

\footnotetext{
${ }^{\S}$ Including nested case-control studies. NA: not available.
} 